\title{
The changing landscape of induction chemotherapy in head and neck cancers
}

\author{
Negi Preety ${ }^{I}$, Srivastava $\mathrm{H}^{2}$, Kingsley $\mathrm{PA}^{3}$ \\ Received on September 30, 2018; editorial approval October 30, 2018
}

\begin{abstract}
In an attempt to improve the survival in locally advanced head and neck carcinomas, varying sequencing of treatment modalities namely surgery, radiation therapy and chemotherapy has been tried. Although concurrent chemoradiotherapy is the standard of care for these patients, induction chemotherapy is considered an effective alternative approach by head and neck oncologists worldwide. Induction chemotherapy continues to be actively pursued because of its potential to control locoregional disease, possible eradication of micrometastasis and organ preservation without jeopardizing overall survival. Inspite of the positive impact of docetaxel-based induction regimens, its direct comparison with the standard treatment failed to show superior results in terms of survival and completion of planned definitive radiation treatment. Several clinical trials have served to clarify the role of induction chemotherapy before definitive treatment in head and neck cancer, still the data remains controversial and warrants randomized controlled trials to ensure that most effective therapy is delivered with subsequent improvement in survival for these patients. This review summarizes key milestones in the evolution of induction chemotherapy in head and neck carcinoma.
\end{abstract}

Keywords: Taxanes; squamous cell carcinoma.

\section{INTRODUCTION}

The treatment of patients with locally advanced head and neck carcinoma (LAHNC) is evolving rapidly. In addition, manuscripts based on author's assessment of the paper's relevance to the topic under consideration were included in this review.

\section{The Evolution of Induction Chemotherapy in Head and} Neck Cancers

In early 1990s, the incorporation of induction chemotherapy
(ICT) before definitive radiotherapy (RT) was extensively investigated as an organ preservation approach particularly for laryngeal or hypopharyngeal carcinomas that would otherwise be managed with surgical approach leading to devastating effect on patient's quality of life. ${ }^{1}$ The landmark Veterans Affair Laryngeal Study Group provided strong evidence supporting the superiority of ICT followed by definitive RT compared with laryngectomy and adjuvant RT in terms of excellent laryngeal preservation (64\%) without compromising overall survival (OS). ${ }^{1}$ Further building upon this, long-term results defined 4 cycles of ICT followed by locoregional treatment to be reserved for patients with inoperable LAHNC only $(\mathrm{p}=0.04){ }^{2}$

The largest [MACH-NC (Meta-Analysis of Chemotherapy in Head and Neck Cancer)] demonstrated significant survival advantage ( $4 \%$ at 5 years) in patients receiving chemotherapy, with an even greater benefit ( $8 \%$ at 5 years) observed in patients undergoing concurrent chemoradiotherapy (CCRT). ${ }^{3}$ The updated analysis showed absolute survival benefit of

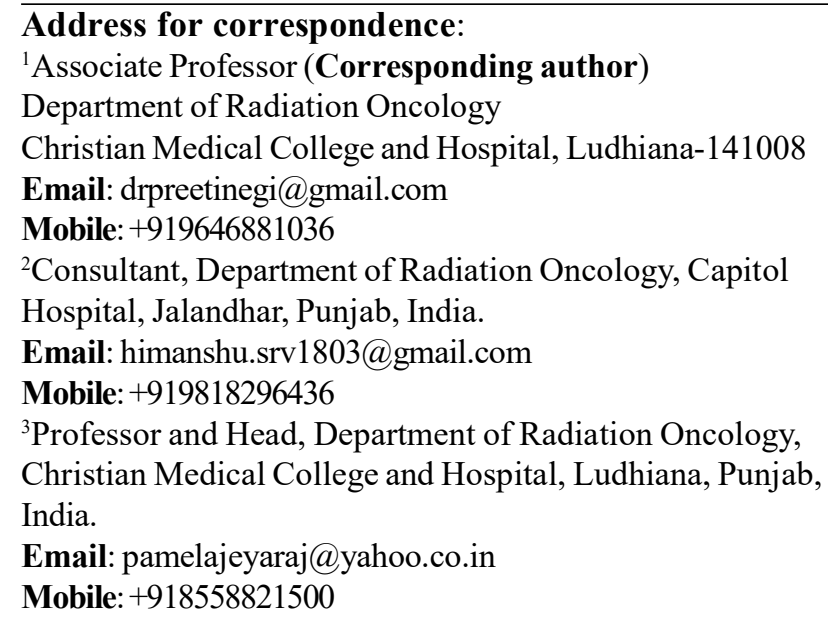
neck cancers. Int J Health Res Medico Leg Prae 2019 January;5(1):3-6. DOI 10.31741/ijhrmlp.v5.i1.2018.2 
$6.5 \%$ at 5 years (HR $0.81,95 \%$ CI $0.78-0.86, \mathrm{p}<0.001$ ) with CCRT was confirmed in comparison to RT alone. The interesting results from this update favoured CCRT while ICT failed to show any survival advantage over the standard of care treatment leading to abandonment of ICT. ${ }^{4}$

\section{Rise of ICT with Taxane-based Regimens}

The research groups compared docetaxel, cisplatin, and 5fluorouracil (TPF)-based regimens with PF regimens thereby reverting our focus towards ICT in the hope of achieving improved outcomes for these patients. ${ }^{5}$ In TAX 323 trial, the addition of docetaxel significantly improved median progression-free survival (PFS) (11.0 vs 8.2 months in the TPF group vs PF group; $p=0.007)$ and a median OS $(18.8$ months in the TPF group vs 14.5 months in the PF group $)^{6}$ TAX 324 trial results reported that despite a better LRC $(\mathrm{p}=$ 0.04 ) and median OS (71 vs 30 months; $p=0.006$ ) with TPF regimen. ${ }^{7}$ The long-term results observed that survival benefit with TPF continues well beyond 2 years of the original analysis. ${ }^{8}$ Groupe d'Oncologie Radiotherapie Tkte Et Cou (GORTEC) 2000-01 trial reported superior results with TPF in terms of overall response rate $(80 \%$ vs $59.2 \% ; \mathrm{p}=0.002)$ and 3 -year actuarial larynx preservation rate $(70.3 \%$ vs $57.5 \% ; \mathrm{p}=0.03) .{ }^{9}$ This benefit with TPF regimen persisted for 10 years. ${ }^{10}$ These landmark studies (TAX 323, TAX 324 and GORTEC laryngeal study) validated the benefit of induction-TPF in terms of OS / PFS, local control, and organ preservation as compared to $\mathrm{PF}$ regimen. However, neither of these trials compared ICT with conventional CCRT.

\section{Impact of ICT on Survival}

Here, we refer to two meta-analysis performed by Zhang et $\mathrm{al}^{11}$ and Kim et al. ${ }^{12} \mathrm{~A}$ meta-analysis of five randomized controlled trials described herein directly addressed this important question by comparing ICT followed by CCRT versus CCRT alone. ${ }^{13-17}$ The investigators found neither statistically significant differences between the two arms regarding OS and PFS, nor any differences as to the incidence of locoregional recurrence rate. They observed a decrease in $\mathrm{DM}$ rate $(\mathrm{RR}=0.58,95 \% \mathrm{CI} 0.39-0.85 ; \mathrm{p}=0.006)$ in the ICT group but this benefit came at the cost of significantly increased risk of grade 3 - 4 febrile neutropenia $(\mathrm{p}=0.0009)$ and leucopenia $(\mathrm{p}=0.04)$, compared with CCRT alone. This meta-analysis failed to demonstrate survival benefit following the addition of ICT to upfront CCRT. ${ }^{11}$ Recently, a larger meta-analysis of six relevant trials comprising 1,280 patients reached similar conclusions of unsatisfactory outcome in terms of OS $(p=0.339)$ for TPF prior to CCRT over CCRT alone. $^{12}$

The two large pioneering randomized controlled trials [PARADIGM and DeCIDE (Docetaxel-Based Chemotherapy Plus or Minus ICT to Decrease Events in Head and Neck Cancer)] needs special mentioning since these trials underscore that CCRT is superior to ICT in LAHNC. ${ }^{14,17}$ The PARADIGM trial ${ }^{14}$ reported no difference between the ICT and CCRT alone group in rates of DM ( $7 \%$ vs $11 \%)$. DeCIDE trial $^{17}$ reported a decrease in DM from $19 \%$ to $10 \%$; however, both studies failed to show an improvement in OS and disease-free survival (DFS) with ICT.

\section{Concerns Regarding ICT}

The added toxicity of this modality might affect compliance to RT in patients with borderline resectable or unresectable head and neck cancer. ${ }^{18-20}$ Patil et a ${ }^{20}$ reported that $15.8 \%$ of patients discontinued ICT after the first cycle. Delay in definitive treatment, interruption of treatment and mortality rate of up to $15.8 \%$ are considered an area of major pitfall with ICT. ${ }^{21,22}$

Both these trials underscore that CCRT is superior to ICT followed by CCRT in LAHNC; and hence, the results of these trials should be interpreted with caution. ${ }^{23}$

It is important to bear in mind that $\mathrm{CT}$ regimen concurrent with RT following ICT might affect the outcome in LAHNC patients. This issue has not been addressed in clinical trials, with as much worth as it should have received. Majority of the trials have used carboplatin (AUC 1.5) or weekly cisplatin $40 \mathrm{mg} / \mathrm{m}^{2}$ concurrent with RT.

\section{Role of ICT in Present Scenario}

ICT has been integrated into multimodality approach in an attempt to improve the cure rates with better functional outcomes. ICT results in significant reduction in the incidence of DM with achievement of higher rates of laryngeal preservation that could not be ignored. ${ }^{24,25}$ Another reason for attractiveness towards ICT could be the fact that patients whose tumours responded to $\mathrm{CT}$ had good response to subsequent RT. ${ }^{26,27}$ ICT seems to be a promising approach in certain clinical scenarios such as laryngeal preservation, unfavourable sites and T3 / T4 or N2 / N3 disease. ${ }^{28-30}$ Other authors have limited its use to patients with good general condition including performance status 0 or 1 , weight loss d" $10 \%$, absence of severe comorbidities, $<70$ years of age. ${ }^{31}$ These data suggest that definitive CCRT should remain the standard of care while ICT should be reserved for patient population likely to receive greatest benefit from this strategy. ${ }^{32,33}$

\section{Conclusions}

The debate regarding the role of ICT in head and neck cancer is an open topic for discussion among the oncology fraternity for more than a decade now. The potential advantages of ICT include organ function preservation in advanced laryngeal or hypopharyngeal carcinomas, controlling micrometastatic disease, providing symptom control before initiating RT and allowing rapid tumour shrinkage in an attempt to avoid emergency procedures. However, an important concern limiting its regular clinical use is the absence of survival benefit. Identification of specific group of patients likely to benefit from ICT is the future of personalized treatment of head and neck cancer.

\section{REFERENCES}

1. Wolf GT, Fisher SG, Hong WK, Hillman R, Spaulding $\mathrm{M}$, Laramore GE, et al. Induction chemotherapy plus radiation compared with surgery plus radiation in patients 
with advanced laryngeal cancer. N Engl J Med 1991;324(24):1685-90.

2. Zorat PL, Paccagnella A, Cavaniglia G, Loreggian L, Gava A, Mione CA, et al. Randomized phase III trial of neoadjuvant chemotherapy in head and neck cancer: 10-year follow-up. J Natl Cancer Inst 2004;96(22):1714-7.

3. Pignon JP, Bourhis J, Domenge C, Designe L. Chemotherapy added to locoregional treatment for head and neck squamous cell carcinoma: three meta-analysis of updated individual data. MACH-NC Collaborative Group. Meta-analysis of chemotherapy on head and neck cancer. Lancet 2000;355(9208):949-55.

4. Pignon JP, le Maitre A, Maillard E, Bourhis J. Metaanalysis of chemotherapy in head and neck cancer (MACH-NC): an update on 93 randomised trials and 17,346 patients. Radiother Oncol 2009;92(1):4-14.

5. Posner MR, Lefebvre JL. Docetaxel induction therapy in locally advanced squamous cell carcinoma of the head and neck. Br J Cancer 2003;88(1):11-7.

6. Vermorken JB, Remenar E, van Herpen C, Gorlia T, Mesia R, Degardin M, et al. Cisplatin, fluorouracil, and docetaxel in unresectable head and neck cancer. N Engl J Med 2007;357(17):1695-704.

7. Posner MR, Hershock DM, Blajman CR, Mickiewicz E, Winquist E, Gorbounova V, et al. Cisplatin and fluorouracil alone or with docetaxel in head and neck cancer. N Engl J Med 2007; 357:1705-15.

8. Lorch JH, Goloubeva O, Haddad RI, Cullen K, Sarlis $\mathrm{N}$, Tishler $\mathrm{R}$, et al. Induction chemotherapy with cisplatin and 5-flurorouracil alone or in combination with docetaxel in locally advanced squamous cell cancer of the head and neck: long-term results of the TAX 324 randomized phase 3 trial. Lancet Oncol 2011;12(2):153-9.

9. Pointreau Y, Garaud P, Chapet S, Sire C, Tuchais C, Tortochaux J, et al. Randomized trial of induction chemotherapy with cisplatin and 5-fluorouracil with or without docetaxel for larynx preservation. J Natl Cancer Inst 2009;101(7):498-506.

10. Janoray G, Pointreau Y, Garaud P, Chapet S, Alfonsi M, Sire C, et al. Long-term results of a multicentre randomized phase III trial of induction chemotherapy with cisplatin, 5-fluorouracil, \pm Docetaxel for larynx preservation. J Natl Cancer Inst 2015;108(4).

11. Zhang L, Jiang N, Shi Y, Li S, Wang P, Zhao Y. Induction chemotherapy with concurrent chemoradiotherapy versus concurrent chemoradiotherapy for locally advanced squamous cell carcinoma of head and neck: a meta-analysis. Sci Rep 2015; 5:10798.

12. Kim R, Hahn S, Shin J, Ock CY, Kim M, Keam B, et al. The effect of induction chemotherapy using docetaxel, cisplatin, and fluorouracil on survival in locally advanced head and neck squamous cell carcinoma: a metaanalysis. Cancer Res Treat 2016;48(3):907-16.
13. Hitt R, Grau JJ, Lopez-Pousa A, Berrocal A, GarciaGiron C, Irigoyen A, et al. A randomized phase III trial comparing induction chemotherapy followed by chemoradiotherapy versus chemoradiotherapy alone as treatment of unresectable head and neck cancer. Ann Oncol 2014;25(1):216-25.

14. Haddad R, O’Neill A, Rabinowits G, Tishler R, Khuri F, Adkins D, et al. Induction chemoradiotherapy followed by concurrent chemoradiotherapy versus concurrent chemoradiotherapy alone in locally advanced head and neck cancer (PARADIGM): a randomised phase 3 trial. Lancet Oncol 2013;14(3):257-64.

15. Paccagnella A, Ghi MG, Loreggian L, Buffoli A, Koussis $\mathrm{H}$, Mione CA, et al. Concomitant chemoradiotherapy versus induction docetaxel, cisplatin and 5-fluorouracil (TPF) followed by concomitant chemoradiotherapy in locally advanced head and neck cancer: a phase II randomized study. Ann Oncol 2010;21(7):1515-22.

16. Chen JW. A randomized control trial of induction chemotherapy combined with concurrent chemoradiotherapy for patients with locally advanced head and neck squamous cell carcinoma. Journal of Chongqing Medical University 2011; 36:1103-6.

17. Cohen EE, Karrison TG, Kocherginsky M, Mueller J, Egan $\mathrm{R}$, Chao $\mathrm{H}$, et al. Phase III randomized trial of induction chemotherapy in patients with N2 or N3 locally advanced head and neck cancer. J Clin Oncol 2014;32(25):2735-43.

18. Balermpas P, Bauer C, Fraunholz I, Ottinger A, Wagenblast J, Stover T, et al. Concomitant chemoradiotherapy versus induction chemotherapy followed by chemoradiotherapy as definitive, first line treatment of squamous cell carcinoma of the head and neck. A retrospective single center analysis. Strahlenther Onkol 2014;190(3):256-62.

19. Huguet F, Schick U, Pointreau Y. Role of induction chemotherapy in head and neck cancer: cons. Cancer Radiother 2017;21(6-7):510-4.

20. Patil VM, Prabhash K, Noronha V, Joshi A, Muddu V, Dhumal S, et al. Neoadjuvant chemotherapy followed by surgery in very locally advanced technically unresectable oral cavity cancers. Oral Oncol 2014;50(10):1000-4.

21. Maka VV, Naga P, Kilara N, Koushik K. Induction chemotherapy for locally advanced head and neck cancer: Retrospective analysis of a single centre experience. Eur J Cancer 2014;50(4):17-8.

22. Caudell JJ, Hamilton RD, Otto KJ, Jennelle RL, Pitman KT, Vijayakumar S. Induction docetaxel, cisplatin, and 5-fluorouracil precludes definitive chemoradiotherapy in a substantial proportion of patients with head and neck cancer in a low socioeconomic status population. Am J Clin Oncol 2014;37(4):332-6.

23. Parsons JT, Greene BD. Induction chemotherapy for 
head and neck squamous cell carcinoma. Oral Oncol 2016;58:e12.

24. Fabregas JC, Loaiza-Bonilla A, Talebi TN, Warsch S, Fernandez G, Raez LE, et al. Concurrent chemoradiotherapy versus induction chemotherapy followed by chemoradiotherapy (sequential approach) in the management of head and neck cancer. Expert Rev Anticancer Ther 2013;13(9):1065-72.

25. Specenier PM, Vermorken JB. Neoadjuvant chemotherapy in head and neck cancer: should it be revisited? Cancer Lett 2007;256:166-77.

26. Calais G. TPF: A rational choice for larynx preservation? The Oncologist 2010;15(3):19-24.

27. Saini SK, Srivastava S, Prasad SN. Response to induction chemotherapy as predictive marker of tumour response to radiotherapy and survival in oral cavity cancer. Clin Cancer Investig J 2015;4:520-4.

28. Ock CY, Keam B, Lim Y, Kim TM, Lee SH, Kwon SK, et al. Effect of induction chemotherapy on survival in locally advanced head and neck carcinoma treated with concurrent chemoradiotherapy: Single center experience. Head Neck 2016;38:277-84.
29. Ove R, Nabell LM. Induction chemotherapy for head and neck cancer: is there still a role? Future Oncol 2016;12(13):1595-608.

30. Sher DJ, Schwartz DL, Nedzi L, Khan S, Hughes R, Fidler MJ, et al. Comparative effectiveness of induction chemotherapy for oropharyngeal squamous cell carcinoma: A population-based analysis. Oral Oncol 2016;54:58-67.

31. Fayette J, Fontaine-Delaruelle C, Ambrun A, Daveau C, Poupart M, Ramade A, et al. Neoadjuvant modified TPF (docetaxel, cisplatin, fluorouracil) for patients unfit to standard TPF in locally advanced head and neck squamous cell carcinoma: a study of 48 patients. Oncotarget 2016;7(24):37297-304.

32. Vidal L, Ben AI, Limon D, Cohen E, Popovtzer A. Role of induction chemotherapy prior to chemoradiation in head and neck squamous cell cancer-Systemic review and meta-analysis. Cancer J 2017;23(2):79-83.

33. DE Felice F, Abate G, Galdieri A, Bulzonetti N, Musio $\mathrm{D}$, Tombolini V. Impact of induction chemotherapy in locally advanced HPV-negative oropharyngeal cancer. A propensity score-matched analysis. Anticancer Res 2016;36(12):6667-72. 